\title{
BMJ Open Country of birth, educational level and other predictors of seeking care due to decreased fetal movements: an observational study in Sweden using data from a cluster-randomised controlled trial
}

\author{
Ingela Radestad, ${ }^{1}$ Karin Pettersson, ${ }^{2}$ Helena Lindgren, ${ }^{3}$ Viktor Skokic, ${ }^{4}$ \\ Anna Akselsson (1D ${ }^{5}$
}

To cite: Radestad I, Pettersson $\mathrm{K}$, Lindgren $\mathrm{H}$, et al. Country of birth, educational level and other predictors of seeking care due to decreased fetal movements: an observational study in Sweden using data from a cluster-randomised controlled trial. BMJ Open 2021;11:e050621. doi:10.1136/ bmjopen-2021-050621

- Prepublication history and additional supplemental material for this paper are available online. To view these files, please visit the journal online (http://dx.doi.org/10.1136/ bmjopen-2021-050621).

Received 25 February 2021 Accepted 11 June 2021

Check for updates

(C) Author(s) (or their employer(s)) 2021. Re-use permitted under CC BY. Published by BMJ.

For numbered affiliations see end of article.

Correspondence to

Dr Anna Akselsson;

anna.akselsson@shh.se

\section{ABSTRACT}

Objectives To identify predictors of seeking care for decreased fetal movements and assess whether careseeking behaviour is influenced by Mindfetalness.

Design Observational study with data from a clusterrandomised controlled trial.

Setting 67 maternity clinics and 6 obstetrical clinics in Sweden.

Participants All pregnant women with a singleton pregnancy who contacted the obstetrical clinic due to decreased fetal movements from 32 weeks' gestation of 39865 women.

Methods Data were collected from a cluster-randomised controlled trial where maternity clinics were randomised to Mindfetalness or routine care. Mindfetalness is a selfassessment method for women to use daily to become familiar with the unborn baby's fetal movement pattern. Outcome measures Predictors for contacting healthcare due to decreased fetal movements.

Results Overall, $5.2 \%(n=2059)$ of women contacted healthcare due to decreased fetal movements, among which 1287 women (62.5\%) were registered at a maternity clinic randomised to Mindfetalness and 772 women $(37.5 \%)$ were randomised to routine care. Predictors for contacting healthcare due to decreased fetal movements were age, country of birth, educational level, parity, prolonged pregnancy and previous psychiatric care $(p<0.001)$. The main differences were seen among women born in Africa as compared with Swedish-born women ( $2 \%$ vs $6 \%$, relative risk (RR) $0.34,95 \% \mathrm{Cl} 0.25$ to 0.44 ) and among women with low educational level compared with women with university-level education ( $2 \%$ vs $5.4 \%$, RR $0.36,95 \% \mathrm{Cl} 0.19$ to 0.62 ). Introducing Mindfetalness in maternity care increased the number of women seeking care due to decreased fetal movements overall.

Conclusion Women with country of birth outside Sweden and low educational level sought care for decreased fetal movements to a lesser extent compared with women born in Sweden and those with university degrees. Future research could explore whether pregnancy outcomes can be improved by motivating women in these groups to contact healthcare if they feel a decreased strength or frequency of fetal movements.
Strengths and limitations of this study

- This is the first study exploring the association between country of birth and contact due to decreased fetal movements.

- The new information about predictors for contacting healthcare due to decreased fetal movements can be valuable for preventing stillbirth.

- Zero lost to follow-up, large sample size and use of a population-based register are methodological strengths.

- Misclassified subjects might have affected the results for the predictors and it is probably an underestimation of the number of women seeking care.

- Possible confounders, not being considered in the study, could have had an impact on the result.

Trial registration number NCT02865759.

\section{INTRODUCTION}

A woman's interpretation of signals from the fetus and her ability to take action will determine whether she contacts healthcare when she has concerns for her unborn baby's health. Her response to altered fetal movement patterns can be decisive for the pregnancy outcomes. Among women who have sought care due to decreased fetal movements, reports indicate that one-quarter will later experience adverse baby outcomes, such as low Apgar score, small for gestational age or stillbirth. ${ }^{1-3}$ Further, up to $50 \%$ of women who experience stillbirth report a gradual decrease in fetal movements several days before the baby died. ${ }^{45}$ The majority waited more than 24 hours before contacting healthcare without the perception of any movements. ${ }^{67}$ Contact with healthcare due to decreased fetal movements is common and most of the women return home after normal 
findings are confirmed. The prevalence of women contacting healthcare with concerns of fetal movements varies internationally; from $6 \%$ to $34 \% .^{8-11}$

Women with normal pregnancies can distinguish between many different types of fetal movements and most feel strong movements. ${ }^{12}$ Maternal perception of fetal movements and becoming familiar with the movement pattern is important in reducing stillbirth, as reported in research from New Zealand. ${ }^{13}$ The character and diurnal rhythm of movements seem to be essential factors in preventing stillbirth. Maternally perceived increased strength of fetal movements is associated with reduced stillbirth rate (adjusted odds ratio (aOR) 0.21, $95 \%$ CI 0.12 to 0.36 ) and quiet or light movements in the evening were associated with higher risk (aOR 3.82, 95\% CI 1.57 to 9.31 ).

Raising maternal awareness of fetal movements by using the Mindfetalness method may be a way forward for women to become familiar with the unborn baby's movement pattern. ${ }^{14}$ Compared with counting methods, ${ }^{15} 16$ Mindfetalness instruct the women to observe the variation of fetal movements. Practicing the method includes to lie down for 15 min a day from 28 weeks' gestation, when the baby is awake and to focus on the character, strength and frequency of the unborn baby's movements, without counting each movement. Mindfetalness was invented in $2012^{14}$ and has been evaluated by women and midwives in two studies. ${ }^{17} 18$ Additionally, in a cluster-randomised controlled trial, 67 maternity clinics were allocated to either Mindfetalness or routine care. ${ }^{19} 20$ Midwives in the Mindfetalness group were instructed to distribute oral and written information about fetal movements and about Mindfetalness. Information regarding the method was available in nine different languages and a website was open for anyone to access. The trial showed several benefits of introducing Mindfetalness into maternity care. ${ }^{19}$ In the Mindfetalness group, more women started their labour spontaneously, followed by a reduction in labour inductions and caesarean sections. Further, less babies were born small for gestational age and needed neonatal care.

The ambition to encourage women to seek care if they have concerns of their unborn baby's fetal movements pattern is to reduce the stillbirth rate without too much overload on both women and caregivers. However, stillbirth is a very rare phenomenon and thus comparing stillbirth rate in this study is impossible. In this study, we investigate predictors of seeking care for decreased fetal movements and whether care-seeking behaviour was influenced by a method (Mindfetalness) aimed at increasing pregnant women's knowledge of their unborn baby's fetal movement patterns. ${ }^{14}$ We further investigate pregnancy outcomes for women seeking care for decreased fetal movements but where, at the time of the examination, no interventions such as induction of labour or caesarean section were made.

\section{METHODS}

Pregnant women with a singleton pregnancy who contacted healthcare due to decreased fetal movements from 32 weeks' gestation constitute the population of this study. Data were collected from a cluster-randomised controlled trial in which 67 maternity clinics in Stockholm, Sweden, were randomised to either intervention with Mindfetalness or routine care, as reported previously. ${ }^{19} 20$ The women who contacted healthcare due to decreased fetal movements from 32 weeks' gestation were generated from the International Classification of Diseases (ICD) code AM041 (examination due to decreased fetal movements). ${ }^{21}$ The code is a diagnosis for pregnant women who have contacted healthcare due to decreased fetal movements, where no interventions, such as labour induction or caesarean section, were made, at the time the woman sought care.

The randomisation resulted in 33 maternity clinics in the Mindfetalness group and 34 maternity clinics in routine care group. After the randomisation, one clinic randomised to Mindfetalness declined participation. We applied intention-to-treat design; extended information about the randomisation process can be found in previous publications. ${ }^{19} 20$ The Mindfetalness group included 19639 women and the routine care group included 20 226 women.

Starting in October 2016, midwives, working at maternity clinics randomised to the intervention, distributed a leaflet to pregnant women, including information about fetal movements and the self-assessment method, Mindfetalness. The last leaflet was distributed on 31 January 2018, and the women were followed-up until birth in population-based registers. Midwives in the routine care group followed standard care, which includes providing oral information about fetal movements at 24 weeks' gestation.

The Mindfetalness leaflet (online supplemental file 3) included information about fetal movements and when to contact healthcare; 'If you are concerned that the fetus is moving less or that the movements are weaker, you should contact healthcare'. Further, the leaflet included an invitation to practice Mindfetalness daily from 28 weeks' gestation. The information was available in nine different languages and the website www.mindfetalness. com was open for anyone to access.

\section{STATISTICAL ANALYSIS}

We identified the background factors of the women who contacted healthcare due to decreased fetal movements by calculating percentages. The included variables were age, country of birth, education level, parity, assisted reproduction, previous stillbirth, tobacco use at registration in maternity clinic, body mass index and maternal diseases. To calculate predictors for contacting healthcare, we investigated which factors were statistically significantly associated with contact due to decreased fetal movements. As a metric for association, we calculated 


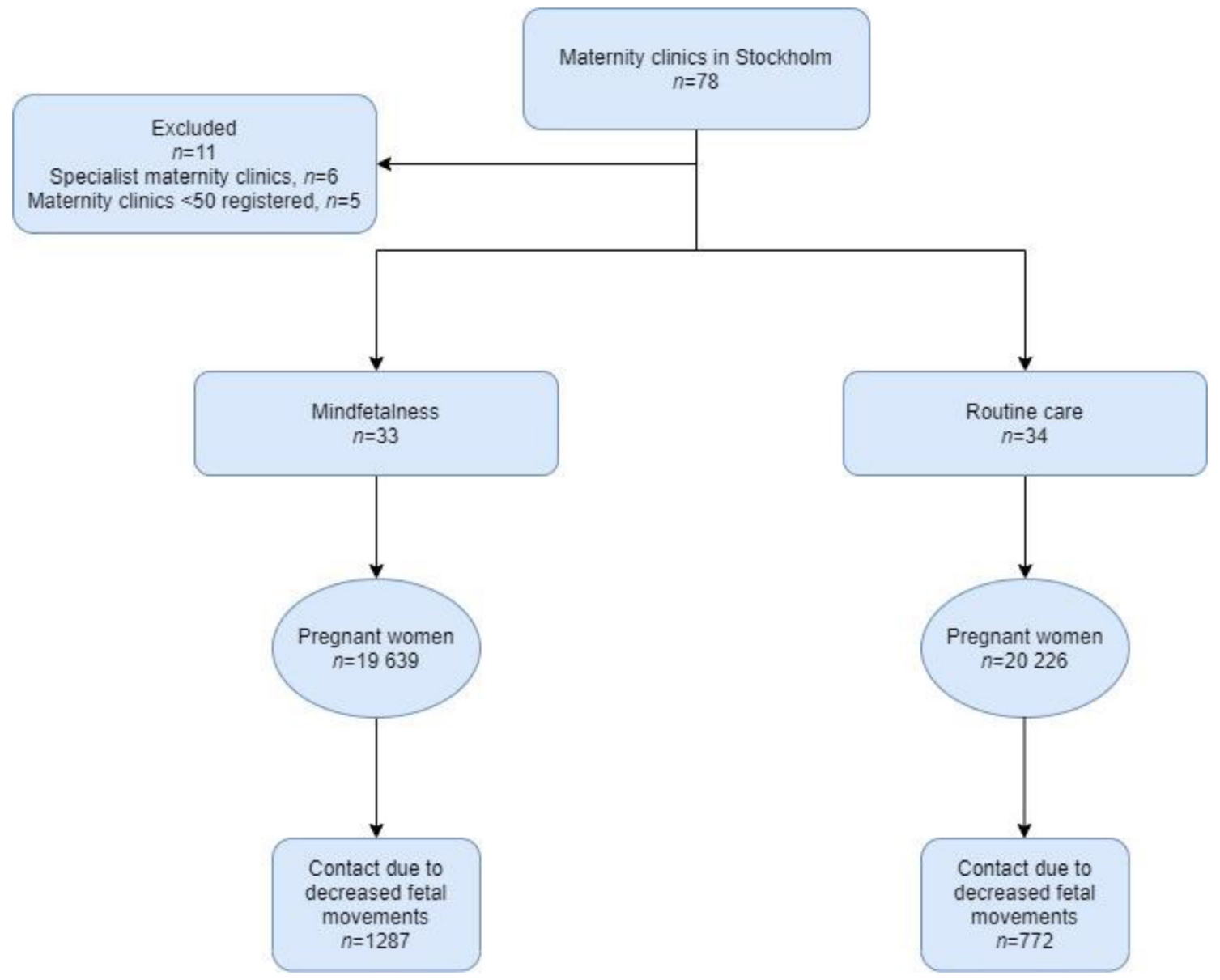

Figure 1 Flow chart.

relative risks (RRs) and 95\% CIs using log-binomial regression. In the predictor calculation, we adjusted for the possible confounding factor, parity. For outcome measures, we calculated percentage and compared the Mindfetalness group with the routine care group using log-binomial regression. We considered a $\mathrm{p}$ value of 0.05 to be statistically significant. We used the statistical programme R (V.3.2.4). Loss to follow-up was zero due to the population-based Swedish Pregnancy Register ${ }^{22}$ used for data collection.

\section{RESULTS}

Among all women in this study, 5.2\% ( $\mathrm{n}=2059)$ contacted healthcare due to decreased fetal movements, measured from gestational week 32 until birth. As shown in figure 1, $62.5 \%(\mathrm{n}=1287)$ were registered at a maternity clinic randomised to Mindfetalness, and $37.5 \% \quad(\mathrm{n}=772)$ to routine care. The background data for the women are displayed in table 1.

Predictors for seeking care for decreased fetal movements were age, country of birth, educational level, parity, prolonged pregnancy and previous psychiatric care $(p<0.001)$ (table 2). The main differences were seen in country of birth and educational levels. Women born in Africa sought care to a lesser extent as compared with women born in Sweden, $2 \%$ vs 6\% (RR $0.34,95 \%$ CI 0.25 to 0.44 ).

Further, women with lowest educational levels sought care due to decreased fetal movements to a lesser extent compared with women with university-level education ( $2 \%$ vs $5.4 \%$, RR $0.36,95 \%$ CI 0.19 to 0.62 ). Additionally, primiparas, women with prolonged pregnancies $(>41+6$ gestation weeks), and women with experience of psychiatric care more often sought care due to decreased fetal movements (table 2). The predictors for contacting healthcare due to decreased fetal movements remain after adjustment for parity. Mindfetalness increased the prevalence of women contacting healthcare due to decreased fetal movements overall $(6.6 \%$ vs $3.8 \%$, RR $1.72,95 \%$ CI 1.57 to 1.87 ) (not in table). When stratifying women into groups according to background factors, the percentage of women contacting healthcare increased in all groups (online supplemental table 1).

Figure 2A,B shows the pregnancy outcomes for women contacting healthcare due to decreased fetal movements, stratified for women registered at maternity clinics randomised to Mindfetalness and routine care, respectively. Compared with routine care, women in the Mindfetalness group had a higher percentage of women with spontaneous start of labour $(66.4 \%$ vs $63 \%)$ and a lower rate of labour induction (25.6\% vs $28.6 \%)$. The 
Table 1 Characteristics among women with a singleton pregnancy from 32 weeks' gestation contacting healthcare versus not contacting healthcare due to decreased fetal movements

\begin{tabular}{|c|c|c|c|c|}
\hline Characteristics & $\begin{array}{l}\text { Contacted healthcare due to } \\
\text { decreased fetal movements } \\
(n=2059) \\
n(\%)\end{array}$ & $\begin{array}{l}\text { Did not contact healthcare due } \\
\text { to decreased fetal movements } \\
(\mathrm{n}=37 \mathrm{806}) \\
\mathrm{n}(\%)\end{array}$ & Relative risk (Cl) & $P$ value \\
\hline \multicolumn{5}{|l|}{$\mathrm{Age}^{*}$} \\
\hline$\leq 24$ years & $187(9.1)$ & $2628(7)$ & 1.31 (1.13 to 1.51$)$ & $<0.001$ \\
\hline $25-34$ years & $1361(66.1)$ & $24137(63.8)$ & 1.04 (1 to 1.07 ) & 0.04 \\
\hline$\geq 35$ years & $511(24.8)$ & 11041 (29.2) & 0.85 (0.79 to 0.92$)$ & $<0.001$ \\
\hline \multicolumn{5}{|l|}{ Country of birth } \\
\hline Sweden & 1595 (77.5) & $24890(65.8)$ & 1.18 (1.15 to 1.21$)$ & $<0.001$ \\
\hline Europe (except Sweden) & $137(6.7)$ & $3780(10)$ & 0.67 (0.56 to 0.79$)$ & $<0.001$ \\
\hline Africa & $51(2.5)$ & $2450(6.5)$ & 0.38 (0.29 to 0.50$)$ & $<0.001$ \\
\hline Asia & 224 (10.9) & $5663(15)$ & 0.73 (0.64 to 0.82 ) & $<0.001$ \\
\hline North America & $16(0.8)$ & $304(0.8)$ & 0.97 (0.59 to 1.60$)$ & 1 \\
\hline South America & $31(1.5)$ & $622(1.6)$ & $0.92(0.64$ to 1.31$)$ & 0.72 \\
\hline Others & $5(0.2)$ & $97(0.3)$ & 0.95 (0.39 to 2.33 ) & 1 \\
\hline \multicolumn{5}{|l|}{ Education level† } \\
\hline Shorter than 9 years & $11(0.5)$ & $551(1.5)$ & 0.36 (0.20 to 0.66$)$ & $<0.001$ \\
\hline Elementary school & $69(3.4)$ & $1734(4.6)$ & 0.72 (0.57 to 0.91$)$ & 0.006 \\
\hline High school & $546(26.5)$ & $9717(25.7)$ & 1.02 (0.95 to 1.10$)$ & 0.64 \\
\hline University & $1290(62.7)$ & $22714(60.1)$ & 1.03 (1 to 1.06$)$ & 0.09 \\
\hline \multicolumn{5}{|l|}{ Parity $\ddagger$} \\
\hline Primipara & $1127(54.7)$ & $16344(43.2)$ & 1.26 (1.21 to 1.32$)$ & $<0.001$ \\
\hline Multipara & $930(45.2)$ & $21324(56.4)$ & 0.80 (0.76 to 0.84$)$ & $<0.001$ \\
\hline Assisted reproduction $\ddagger$ & $129(6.3)$ & $2033(5.4)$ & 1.17 (0.98 to 1.38$)$ & 0.09 \\
\hline Previous stillbirth & $9(0.4)$ & $211(0.6)$ & 0.78 (0.40 to 1.52$)$ & 0.64 \\
\hline $\begin{array}{l}\text { Tobacco user at } \\
\text { registration in the maternity } \\
\text { clinic (including snuff) } \ddagger\end{array}$ & $79(3.8)$ & $1256(3.3)$ & 1.16 (0.92 to 1.44$)$ & 0.21 \\
\hline \multicolumn{5}{|l|}{ Body mass index§ } \\
\hline$<18.5 \mathrm{~kg} / \mathrm{m}^{2}$ & $54(2.6)$ & $1021(2.7)$ & 0.97 (0.74 to 1.27$)$ & 0.89 \\
\hline $18.5-24.9 \mathrm{~kg} / \mathrm{m}^{2}$ & $1228(59.6)$ & $22624(59.8)$ & 0.99 (0.96 to 1.03$)$ & 0.70 \\
\hline $25-29.9 \mathrm{~kg} / \mathrm{m}^{2}$ & $464(22.5)$ & 8611 (22.8) & 0.99 (0.91 to 1.07$)$ & 0.74 \\
\hline $30-34.9 \mathrm{~kg} / \mathrm{m}^{2}$ & $167(8.1)$ & $2889(7.6)$ & 1.06 (0.91 to 1.23$)$ & 0.47 \\
\hline$\geq 35 \mathrm{~kg} / \mathrm{m}^{2}$ & $63(3.1)$ & $1000(2.6)$ & 1.15 (0.90 to 1.48$)$ & 0.26 \\
\hline \multicolumn{5}{|l|}{ Maternal diseases } \\
\hline Diabetes mellitus & $1(0)$ & $63(0.2)$ & 0.29 (0.04 to 2.10$)$ & 0.26 \\
\hline Coronary heart disease & $25(1.2)$ & $600(1.6)$ & 0.77 (0.51 to 1.14$)$ & 0.20 \\
\hline Thrombosis & $13(0.6)$ & $283(0.7)$ & 0.84 (0.49 to 1.47$)$ & 0.69 \\
\hline $\begin{array}{l}\text { Systemic lupus } \\
\text { erythematosus }\end{array}$ & $1(0)$ & $58(0.2)$ & 0.32 (0.04 to 2.28$)$ & 0.37 \\
\hline Psychiatric care & $354(17.2)$ & 4744 (12.5) & 1.37 (1.24 to 1.51$)$ & $<0.001$ \\
\hline Endocrine disease & $156(7.6)$ & $2633(7)$ & 1.09 (0.93 to 1.27$)$ & 0.29 \\
\hline Epilepsy & $10(0.5)$ & $167(0.4)$ & 1.10 (0.58 to 2.08$)$ & 0.73 \\
\hline Chronic hypertension & $9(0.4)$ & $184(0.5)$ & 0.90 (0.46 to 1.75$)$ & 0.87 \\
\hline Other disease & $204(9.9)$ & $3583(9.5)$ & 1.05 (0.91 to 1.20$)$ & 0.51 \\
\hline
\end{tabular}




\begin{tabular}{|c|c|c|c|c|}
\hline Characteristics & $\begin{array}{l}\text { Contacted healthcare due to } \\
\text { decreased fetal movements } \\
(n=2059) \\
n(\%)\end{array}$ & $\begin{array}{l}\text { Did not contact healthcare due } \\
\text { to decreased fetal movements } \\
(\mathrm{n}=37806) \\
n(\%)\end{array}$ & Relative risk (Cl) & $P$ value \\
\hline $\begin{array}{l}\text { Medication or } \\
\text { psychological treatment } \\
\text { for mental illness }\end{array}$ & $129(6.3)$ & $2058(5.4)$ & $1.15(0.97$ to 1.37$)$ & 0.11 \\
\hline
\end{tabular}

*Mean age of women who contacted care=31.2, who did not contact care $=32.4(p<0.001)$.

†Data missing for women who contacted care $n=143(6.9 \%)$, who did not contact care $n=3090(8.2 \%)$.

fData missing for women who contacted care $n=2(0.1 \%)$, who did not contact care $n=138(0.4 \%)$.

$\S$ Data missing for women who contacted care $n=83(4 \%)$, who did not contact care $n=1661(4.4 \%)$.

proportion of women who had onset of labour from 42 weeks' gestation was $6.8 \%$ in the Mindfetalness group, and $7.8 \%$ in routine care. Further, a lower proportion of babies in the Mindfetalness group were in need of transfer to neonatal intensive care unit $(6.3 \%$ vs $8 \%)$. One stillbirth was observed, in the routine care group (not in table). There were no statistically significant differences in the investigated pregnancy outcomes in figure 2A,B, between the Mindfetalness and routine care groups. For further information in pregnancy outcomes for Mindfetalness and routine care, see online supplemental table 2.

\section{DISCUSSION}

During the studied period, in the Stockholm region, women born outside Sweden and women with low levels of education sought care for decreased fetal movements to a lower extent when compared with women born in Sweden and women with university-level education. Further, women of higher age contacted healthcare due to decreased fetal movements to a lower extent than women of a younger age. Country of birth outside Sweden, low educational level and advanced maternal age have previously been related to adverse birth outcomes. Introducing Mindfetalness in maternity care increased the number of women contacting healthcare due to decreased fetal movements.

We found that women born outside Sweden (mostly from Africa and Asia) sought care due to decreased fetal movements to a lower extent. No studies, to our knowledge, have investigated the association between contact with healthcare due to maternal concern of fetal movements and country of birth. However, previous research has reported a higher risk of stillbirth among women not being born, but giving birth, in a Western country. ${ }^{23-28}$ Suggested mechanisms for this difference include substandard maternity care, lack of communication between the pregnant woman and healthcare professionals and variations in pre-pregnancy health. ${ }^{24}{ }^{29} \mathrm{It}$ is possible that the higher risk for stillbirth can be linked to lower awareness and knowledge about fetal movements and when to contact healthcare. ${ }^{67}$

Giving information to pregnant women about fetal movements may reduce pre-hospital delays ${ }^{30-32}$ and has been suggested to reduce the stillbirth rate in an intervention study performed in Norway. ${ }^{32}$ The study documented a $50 \%$ reduction in the stillbirth rate among women who contacted healthcare due to decreased fetal movements as compared with women who did not. The intervention included providing health promotion information to the pregnant women, an invitation to count fetal movements, and information that they should never wait until the next day to contact healthcare if they had concerns about fetal movements. Additionally, providing new guidelines to the healthcare professionals was included in the intervention. A reduction in patient delay and increased knowledge about fetal movements was shown in a recent study from the Netherlands after the introduction of a leaflet about fetal movements. ${ }^{33}$ However, in the AFFIRM trial, ${ }^{34}$ women in the intervention arm (including information to pregnant women and new guidelines to the healthcare professionals) had lower rate of stillbirths than women in the control group, but the difference was not statistically significant. Labour inductions and caesarean section increased, and the number of babies in need of neonatal care more than 48 hours.

The midwife is the most important source of information $^{35} 36$ and The Swedish National Board of Health and Welfare recently introduced new guidelines for maternity care, including instructions to midwives to inform pregnant women about fetal movements. ${ }^{37}$ The guidelines have good compliance among midwives (79\%-87\% answered yes to the different questions whether they followed the guidelines), but some report barriers due to lack of time, high workload and problems in communicating with women born outside of Sweden. ${ }^{38}$ Suboptimal care is more common among non-western women and action to improve perinatal mortality for this group is needed. ${ }^{24}$

In this study, women with low education levels sought care due to decreased fetal movements to a lower extent, as compared with women with high education levels. A higher risk for stillbirth has been found among women with low educational levels and low socioeconomic status. $^{6}{ }^{39-41}$ There are reasons to believe that raising awareness about fetal movements among women with low education or socioeconomic status would increase the 
Table 2 Predictors for contacting healthcare due to decreased fetal movements

\begin{tabular}{|c|c|c|c|c|c|}
\hline Predictor & $P$ value & n (\%) & RR (Cl) & $P$ value & Adjusted RR (Cl)* \\
\hline Age & $<0.001$ & & & 0.02 & \\
\hline$\leq 24$ years & & $187(6.6)$ & 1.24 (1.07 to 1.44$)$ & & 1.15 (0.98 to 1.33$)$ \\
\hline $25-34$ years & & $1361(5.3)$ & 1 (Reference) & & 1 (Reference) \\
\hline$\geq 35$ years & & $511(4.4)$ & 0.83 (0.75 to 0.91$)$ & & $0.90(0.82$ to 1$)$ \\
\hline Country of birth & $<0.001$ & & & $<0.001$ & \\
\hline Sweden & & $1595(6)$ & 1 (Reference) & & 1 (Reference) \\
\hline Europe (except Sweden) & & $137(3.5)$ & 0.58 (0.49 to 0.69$)$ & & 0.58 (0.49 to 0.69$)$ \\
\hline Africa & & $51(2)$ & 0.34 (0.25 to 0.44$)$ & & $0.36(0.27$ to 0.47$)$ \\
\hline Asia & & $224(3.8)$ & 0.63 (0.55 to 0.72$)$ & & 0.66 (0.57 to 0.75$)$ \\
\hline North America & & $16(5)$ & 0.83 (0.49 to 1.29$)$ & & 0.83 (0.49 to 1.28$)$ \\
\hline South America & & $31(4.7)$ & 0.79 (0.54 to 1.09$)$ & & 0.82 (0.56 to 1.13$)$ \\
\hline Others & & $5(4.9)$ & 0.81 (0.30 to 1.70$)$ & & $0.84(0.31$ to 1.75$)$ \\
\hline Marital status & 0.20 & & & 0.06 & \\
\hline Cohabiting with becoming father & & $1914(5.2)$ & 1 (Reference) & & 1 (Reference) \\
\hline Single & & $29(4)$ & 0.76 (0.52 to 1.07$)$ & & 0.73 (0.49 to 1.02$)$ \\
\hline Other family situation & & $114(4.8)$ & 0.92 (0.76 to 1.10$)$ & & 0.87 (0.72 to 1.04$)$ \\
\hline Education level & $<0.001$ & & & $<0.001$ & \\
\hline Shorter than 9 years & & $11(2)$ & 0.36 (0.19 to 0.62$)$ & & 0.41 (0.21 to 0.69$)$ \\
\hline Elementary school & & $69(3.8)$ & 0.71 (0.56 to 0.90$)$ & & 0.75 (0.58 to 0.94$)$ \\
\hline High school & & $546(5.3)$ & $0.99(0.90$ to 1.09$)$ & & 1 (0.91 to 1.10$)$ \\
\hline University & & $1290(5.4)$ & 1 (Reference) & & 1 (Reference) \\
\hline Parity & $<0.001$ & & & NA & \\
\hline Primipara & & $1127(6.5)$ & 1.54 (1.42 to 1.68$)$ & & NA \\
\hline Multipara & & $930(4.2)$ & 1 (Reference) & & NA \\
\hline Gestation week $>41+6$ & $<0.001$ & & & 0.01 & \\
\hline No & & & 1 (Reference) & & 1 (Reference) \\
\hline Yes & & & 1.34 (1.13 to 1.56$)$ & & 1.25 (1.06 to 1.46$)$ \\
\hline Assisted reproduction & 0.10 & & & 0.55 & \\
\hline No & & $1928(5.1)$ & 1 (Reference) & & 1 (Reference) \\
\hline Yes & & $129(6)$ & 1.16 (0.97 to 1.38$)$ & & 1.05 (0.88 to 1.25$)$ \\
\hline Previous stillbirth & 0.46 & & & 0.95 & \\
\hline No & & $2050(5.2)$ & 1 (Reference) & & 1 (Reference) \\
\hline Yes & & $9(4.1)$ & 0.79 (0.38 to 1.41$)$ & & 0.98 (0.47 to 1.74$)$ \\
\hline $\begin{array}{l}\text { Tobacco user at registration at the } \\
\text { maternity clinic }\end{array}$ & 0.22 & & & 0.17 & \\
\hline No & & & 1 (Reference) & & 1 (Reference) \\
\hline Yes & & $79(5.9)$ & 1.15 (0.92 to 1.42$)$ & & 1.17 (0.93 to 1.44$)$ \\
\hline Body mass index & 0.77 & & & 0.37 & \\
\hline$<18.5 \mathrm{~kg} / \mathrm{m}^{2}$ & & $54(5)$ & 0.98 (0.74 to 1.26$)$ & & 0.95 (0.72 to 1.23$)$ \\
\hline $18.5-24.9 \mathrm{~kg} / \mathrm{m}^{2}$ & & $1228(5.1)$ & 1 (Reference) & & 1 (Reference) \\
\hline $25-29.9 \mathrm{~kg} / \mathrm{m}^{2}$ & & $464(5.1)$ & 0.99 (0.89 to 1.10$)$ & & 1.03 (0.92 to 1.14$)$ \\
\hline $30-34.9 \mathrm{~kg} / \mathrm{m}^{2}$ & & $167(5.5)$ & 1.06 (0.90 to 1.24$)$ & & 1.12 (0.95 to 1.31$)$ \\
\hline$\geq 35 \mathrm{~kg} / \mathrm{m}^{2}$ & & $63(5.9)$ & 1.15 (0.89 to 1.46$)$ & & 1.22 (0.94 to 1.54$)$ \\
\hline Psychiatric care & $<0.001$ & & & $<0.001$ & \\
\hline No & & $1705(4.9)$ & 1 (Reference) & & 1 (Reference) \\
\hline
\end{tabular}


Table 2 Continued

\begin{tabular}{|c|c|c|c|c|c|}
\hline Predictor & $P$ value & $\mathrm{n}(\%)$ & $\mathrm{RR}(\mathrm{Cl})$ & $P$ value & Adjusted RR (Cl)* \\
\hline Yes & & 354 (6.9) & 1.42 (1.27 to 1.58$)$ & & 1.37 (1.22 to 1.52$)$ \\
\hline $\begin{array}{l}\text { Medication or psychological treatment for } \\
\text { mental illness }\end{array}$ & 0.12 & & & 0.13 & \\
\hline No & & $1930(5.1)$ & 1 (Reference) & & 1 (Reference) \\
\hline Yes & & $129(5.9)$ & 1.15 (0.96 to 1.36$)$ & & 1.15 (0.96 to 1.36$)$ \\
\hline
\end{tabular}

${ }^{*}$ Adjusted for parity.

$\mathrm{RR}$, relative risk.

number of women seeking care due to decreased fetal movements, which in turn would possibly decrease perinatal mortality.

Women of advanced maternal age contacted healthcare due to decreased fetal movements to a lower extent than younger women in our study, and a higher risk of stillbirth is reported among women aged from 35 years compared with younger women. ${ }^{42}$ The mean age in an Israeli study was lower among women who had contacted

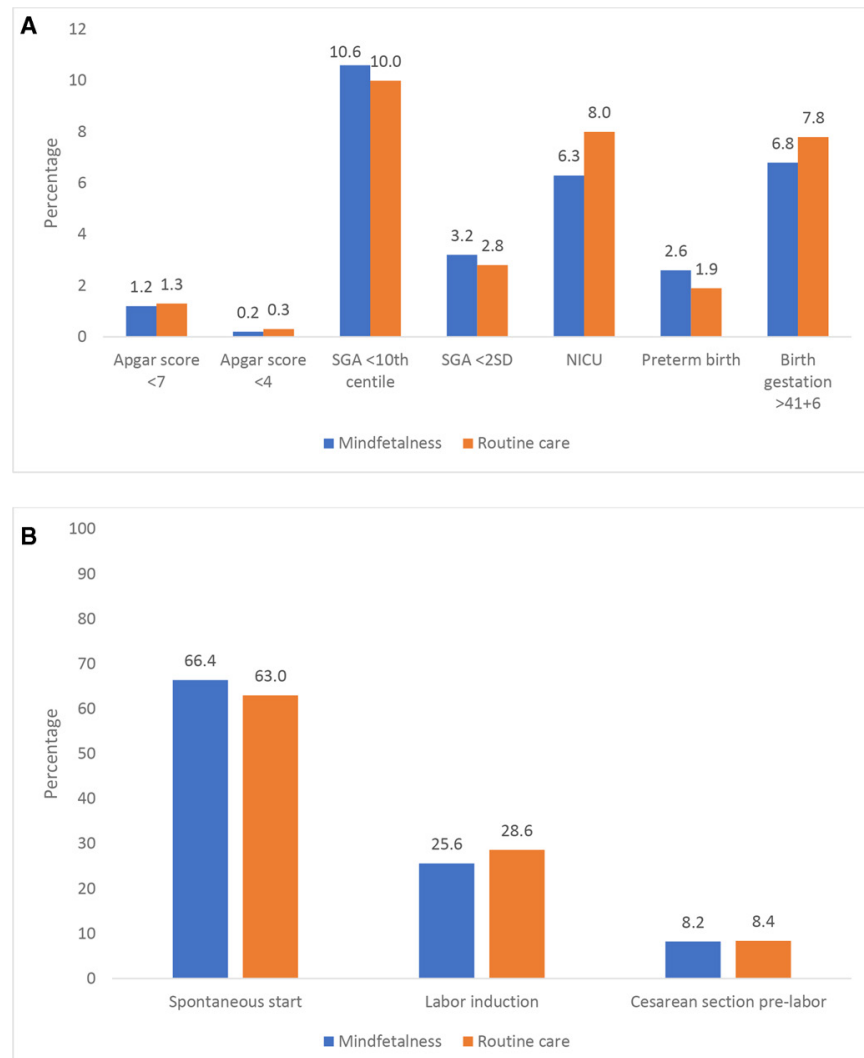

Figure 2 (A) Birth outcome among women who contacted healthcare due to decreased fetal movements from 32 weeks' gestation, where the examination did not indicate that the pregnancy needed to be terminated, at the time the women sought care. (B) Start of labour among women who contacted healthcare due to decreased fetal movements from 32 weeks' gestation, where the examination did not indicate that the pregnancy needed to be terminated, at the time the women sought care. NICU, neonatal intensive care unit. SGA, small for gestational age. healthcare due to decreased fetal movements compared with the reference group. ${ }^{43}$ In a study from Norway, the percentage of women over 35 years of age was lower among women who contacted healthcare due to decreased fetal movements compared with the reference group $(16 \%$ vs $20 \%) .^{3}$ However, in a recent systematic review, the authors interpreted current evidence as not supporting the notion that a woman's mean age influences whether she seeks care for decreased fetal movements. ${ }^{44}$

Introducing Mindfetalness in maternity care increased the number of women contacting healthcare due to decreased fetal movements overall. Mindfetalness possibly increases the woman's ability to become familiar with the unborn baby's fetal movement patterns. Reducing prehospital delay when the perception that fetal movements are reduced is suggested to be one way for improving perinatal mortality. 73031

\section{METHODOLOGICAL CONSIDERATIONS}

The prevalence of women seeking care due to decreased or altered fetal movements in our study is low compared with the figures from other research. In a study performed in Sweden in 2014, 9.3\% of the women sought care due to decreased fetal movements when measured from gestational week 28 until birth. ${ }^{9}$ Further, international studies show a prevalence of $6 \%-34 \% .{ }^{8101145}$ We believe that the figures in our study are underestimated, mostly due to the fact that we only included women who sought care from gestational week 32. Additionally, the ICD code AM041 is not the best tool to use for including all women who contact healthcare due to decreased fetal movements, but it is the only code available. Misclassification in the study may be important to consider as some women who sought care due to decreased fetal movements did not get the ICD code and were classified as they had not sought care. This might have diluted the differences between the groups of women who sought/not sought care due to decreased fetal movements. However, when comparing the Mindfetalness group with routine care group, only non-differential misclassification is likely, which effect the differences in the same way in the two groups.

The only potential confounder we adjusted for was parity. We do not have information about other possibly confounders, for example, if some of the women had 
extra appointments in specialist maternity clinics, which may have affected their care-seeking behaviour. Extra prebooked meetings with midwives or obstetricians and investigations with cardiotocography or ultrasound due to other complication can also decrease the need for unscheduled visits at the hospitals.

When evaluating whether Mindfetalness has an effect on women contacting healthcare due to decreased fetal movements, the random allocation, the large sample size and zero lost to follow-up are strengths of the study. Further, the missing data are negligible, thanks to the unique population-based register in Sweden. While the intention-to-treat design does preserve the advantages of random allocation, it also risks misclassification and the dilution of the results, that is, it is an underestimation of the true effects. From the pilot study, we know that approximately $75 \%$ of the Swedish-speaking women use the method, ${ }^{17}$ and, from the main trial, about $22 \%$ did not receive a leaflet. ${ }^{19}$ Additionally, the information was available in nine languages and, in Stockholm, Sweden, there is a large variety of women who originate from different countries and who speak languages that were not included in the intervention and this may have diluted the effect. This further contributes to the possible dilution of effects.

Less likely to seek care were (1) women 35 and over, (2) less educated and (3) non-Swedish women. Women using Mindfetalness were more likely to visit healthcareproviders due to decreased fetal movements than women in the control-group. It is unclear from this study whether we would have seen the same results if we had used a conventional 'count to ten' approach to maternal awareness of fetal movements

\section{IMPLICATIONS}

The National Board of Health and Welfare claim that pregnant women should receive information about risk factors for adverse pregnancy outcomes, including stillbirth. ${ }^{38}$ Women born in low-income countries and women with advanced maternal age are factors to consider when trying to improve perinatal mortality in high-income countries. ${ }^{42} 46$ Providing targeted information, available in a variety of languages, to these women about fetal movements and when to contact healthcare might help to improve perinatal outcomes. Also, providing information about how to practice Mindfetalness can be one way forward to reduce adverse pregnancy outcomes. Today, we have a great number of opportunities to reach pregnant women thanks to the internet and to target women in at-risk groups. Additionally, this information can be provided in different forms, for example, videos, apps and interactive webpages.

\section{CONCLUSION}

We do not know for certain what the ideal frequency is for women seeking care due to decreased fetal movements, but we can conclude that it is lower in women who have migrated to Sweden from, for example, Africa and Asia, and in women with low educational levels. Women from low-income countries have documented worse pregnancy outcomes. An implication of our results may be to examine whether pregnancy outcomes can be improved by providing customised information to women from low-income countries with the goal that they seek care if they feel a decreased strength or frequency of fetal movements. More data are needed to draw conclusions about the effects of Mindfetalness in perinatal mortality among women contacting healthcare due to decreased fetal movements.

\section{Author affiliations}

${ }^{1}$ Reproductive Health, Sophiahemmet University, Stockholm, Sweden

${ }^{2}$ Department of Clinical Science, Intervention and Technology, Karolinska Institute, Stockholm, Sweden

${ }^{3}$ Women's and Children's Health, Karolinska Institute, Stockholm, Sweden ${ }^{4}$ Institute of Clinical Sciences, Sahlgrenska Academy, University of Gothenburg, Goteborg, Sweden

${ }^{5}$ Health Promoting Science, Sophiahemmet University, Stockholm, Sweden

\section{Twitter Anna Akselsson @AnnaAkselsson}

Acknowledgements The authors would like to thank the midwives and the pregnant women in the maternity clinics in Stockholm. Thanks to the coordination of midwives and medical doctors at Mödrahälsovårdsenheten and to The Swedish Pregnancy Register for cooperation. Special thanks to The Swedish Research Council for funding this study.

Contributors IR, KP, HL and AA were involved in the design and planning of the cluster-randomised controlled trial and IR obtained funding. AA had overall responsibility for the study. VS and AA analysed the data with input from IR, KP and $\mathrm{HL}$. AA wrote the original manuscript and all authors made critical input. All authors were responsible for drafting and validating the following versions of the manuscript. All authors approved the final version of the manuscript.

Funding This study was funded by The Swedish Research Council. Grant number not applicable.

Competing interests None declared.

Patient consent for publication Not required.

Ethics approval This study was approved by the Regional Ethics committee in Stockholm, Sweden (Dnr 2015/2105-31/1), 13 January 2016.

Provenance and peer review Not commissioned; externally peer reviewed.

Data availability statement Data may be obtained from a third party and are not publicly available. No additional data is available. Anonymised data are available after ethical approval by the Regional Ethics committee in Stockholm, Sweden, and after request to The Swedish Pregnancy Register.

Supplemental material This content has been supplied by the author(s). It has not been vetted by BMJ Publishing Group Limited (BMJ) and may not have been peer-reviewed. Any opinions or recommendations discussed are solely those of the author(s) and are not endorsed by BMJ. BMJ disclaims all liability and responsibility arising from any reliance placed on the content. Where the content includes any translated material, BMJ does not warrant the accuracy and reliability of the translations (including but not limited to local regulations, clinical guidelines, terminology, drug names and drug dosages), and is not responsible for any error and/or omissions arising from translation and adaptation or otherwise.

Open access This is an open access article distributed in accordance with the Creative Commons Attribution 4.0 Unported (CC BY 4.0) license, which permits others to copy, redistribute, remix, transform and build upon this work for any purpose, provided the original work is properly cited, a link to the licence is given, and indication of whether changes were made. See: https://creativecommons.org/ licenses/by/4.0/.

ORCID iD

Anna Akselsson http://orcid.org/0000-0003-0830-217X 


\section{REFERENCES}

1 Dutton PJ, Warrander LK, Roberts SA, et al. Predictors of poor perinatal outcome following maternal perception of reduced fetal movements--a prospective cohort study. PLoS One 2012;7:e39784.

2 Higgins LE, Myers JE, Sibley CP, et al. Antenatal placental assessment in the prediction of adverse pregnancy outcome after reduced fetal movement. PLoS One 2018;13:e0206533.

3 Holm Tveit JV, Saastad E, Stray-Pedersen B, et al. Maternal characteristics and pregnancy outcomes in women presenting with decreased fetal movements in late pregnancy. Acta Obstet Gynecol Scand 2009;88:1345-51.

4 Linde A, Pettersson K, Rådestad I. Women's Experiences of Fetal Movements before the Confirmation of Fetal Death--Contractions Misinterpreted as Fetal Movement. Birth 2015;42:189-94.

5 Warland J, O'Brien LM, Heazell AEP, et al. An international Internet survey of the experiences of 1,714 mothers with a late stillbirth: the stars cohort study. BMC Pregnancy Childbirth 2015;15:172.

6 Frøen JF, Arnestad M, Frey K, et al. Risk factors for sudden intrauterine unexplained death: epidemiologic characteristics of singleton cases in Oslo, Norway, 1986-1995. Am J Obstet Gynecol 2001;184:694-702.

7 Koshida S, Ono T, Tsuji S, et al. Excessively delayed maternal reaction after their perception of decreased fetal movements in stillbirths: population-based study in Japan. Women Birth 2017;30:468-71.

8 Kapaya H, Almeida J, Karouni F, et al. Management of reduced fetal movement: a comparative analysis of two audits at a tertiary care clinical service. Eur J Obstet Gynecol Reprod Biol 2020;248:128-32.

9 Akselsson A, Lindgren H, Georgsson S, et al. Increased labor induction and women presenting with decreased or altered fetal movements - a population-based survey. PLoS One 2019;14:e0216216.

10 Frøen JF. A kick from within--fetal movement counting and the cancelled progress in antenatal care. J Perinat Med 2004;32:13-24.

11 Sergent F, Lefèvre A, Verspyck E, et al. [Decreased fetal movements in the third trimester: what to do?]. Gynecol Obstet Fertil 2005;33:861-9.

12 Rådestad I, Lindgren H. Women's perceptions of fetal movements in full-term pregnancy. Sex Reprod Healthc 2012;3:113-6.

13 Bradford BF, Cronin RS, McCowan LME, et al. Association between maternally perceived quality and pattern of fetal movements and late stillbirth. Sci Rep 2019;9:9815.

14 Rådestad I. Strengthening mindfetalness. Sex Reprod Healthc 2012;3:59-60.

15 Pearson JF. Fetal movements--a new approach to antenatal care. Nurs Mirror Midwives J 1977;144:49-51.

16 Sadovsky E, Yaffe H. Daily fetal movement recording and fetal prognosis. Obstet Gynecol 1973;41:845-50.

17 Akselsson A, Georgsson S, Lindgren $\mathrm{H}$, et al. Women's attitudes, experiences and compliance concerning the use of Mindfetalnessa method for systematic observation of fetal movements in late pregnancy. BMC Pregnancy Childbirth 2017;17:359.

18 Malm M-C, Rådestad I, Rubertsson C, et al. Women's experiences of two different self-assessment methods for monitoring fetal movements in full-term pregnancy--a crossover trial. BMC Pregnancy Childbirth 2014;14:349.

19 Akselsson A, Lindgren H, Georgsson S, et al. Mindfetalness to increase women's awareness of fetal movements and pregnancy outcomes: a cluster-randomised controlled trial including 39865 women. BJOG 2020;127:829-37.

20 Rådestad I, Akselsson A, Georgsson S, et al. Rationale, study protocol and the cluster randomization process in a controlled trial including 40,000 women investigating the effects of mindfetalness. Sex Reprod Healthc 2016;10:56-61.

21 Icd internetmedicin I Göteborg ab. Available: http://icd. internetmedicin.se/ [Accessed Dec 2020].

22 Graviditetsregistret. Available: https://www.medscinet.com/gr/ engelska.aspx [Accessed Jan 2021].

23 Gagnon AJ, Zimbeck M, Zeitlin J, et al. Migration to Western industrialised countries and perinatal health: a systematic review. Soc Sci Med 2009;69:934-46.
24 Saastad E, Vangen S, Frøen JF. Suboptimal care in stillbirths - a retrospective audit study. Acta Obstet Gynecol Scand 2007;86:444-50.

25 Khalil A, Rezende J, Akolekar R, et al. Maternal racial origin and adverse pregnancy outcome: a cohort study. Ultrasound Obstet Gynecol 2013;41:278-85.

26 Ravelli ACJ, Tromp M, Eskes M, et al. Ethnic differences in stillbirth and early neonatal mortality in the Netherlands. J Epidemiol Community Health 2011;65:696-701.

27 Drysdale $\mathrm{H}$, Ranasinha S, Kendall A, et al. Ethnicity and the risk of late-pregnancy stillbirth. Med J Aust 2012;197:278-81.

28 Vik ES, Aasheim V, Schytt E, et al. Stillbirth in relation to maternal country of birth and other migration related factors: a populationbased study in Norway. BMC Pregnancy Childbirth 2019;19:5.

29 Essén B, Bödker B, Sjöberg NO, et al. Are some perinatal deaths in immigrant groups linked to suboptimal perinatal care services? BJOG 2002;109:677-82.

30 Koshida S, Ono T, Tsuji S, et al. Recommendations for preventing stillbirth: a regional population-based study in Japan during 20072011. Tohoku J Exp Med 2015;235:145-9.

31 RCOG. Reduced fetal movements, 2011. Available: https://www. rcog.org.uk/en/guidelines-research-services/guidelines/gtg57/57 [Accessed Dec 2020].

32 Tveit JVH, Saastad E, Stray-Pedersen B, et al. Reduction of late stillbirth with the introduction of fetal movement information and guidelines - a clinical quality improvement. BMC Pregnancy Childbirth 2009;9:32

33 Wackers KJWM, Wassen MMLH, Zeegers B, et al. Effect of the use of a national information brochure about fetal movements on patient delay. Women Birth 2019;32:131-6.

34 Norman JE, Heazell AEP, Rodriguez A, et al. Awareness of fetal movements and care package to reduce fetal mortality (affirm): a stepped wedge, cluster-randomised trial. Lancet 2018;392:1629-38.

35 Grimes HA, Forster DA, Newton MS. Sources of information used by women during pregnancy to meet their information needs. Midwifery 2014;30:e26-33.

36 McArdle A, Flenady V, Toohill J, et al. How pregnant women learn about foetal movements: sources and preferences for information. Women Birth 2015;28:54-9.

37 Socialstyrelsen. Minskade fosterrörelser - rekommendationer Om information, råd och en inledande bedömning - Kunskapsstöd Med nationella rekommendationer, 2016. Available: http://www. socialstyrelsen.se/publikationer2016/2016-10-9 [Accessed Dec 2020].

38 Socialstyrelsen. Dödfödda barn - En inventering och förslag på åtgärder, 2018. Available: https://www.socialstyrelsen.se/ publikationer2018/2018-12-36/Sidor/default.aspx [Accessed Jan 2021].

39 Stephansson O, Dickman PW, Johansson AL, et al. The influence of socioeconomic status on stillbirth risk in Sweden. Int J Epidemiol 2001;30:1296-301.

40 Zeitlin J, Mortensen L, Prunet C, et al. Socioeconomic inequalities in stillbirth rates in Europe: measuring the gap using routine data from the Euro-Peristat project. BMC Pregnancy Childbirth 2016;16:15.

41 Socialstyrelsen. Socioekonomiska faktorers påverkan på kvinnors och barns hälsa efter förlossning, 2016. Available: https://www. socialstyrelsen.se/globalassets/sharepoint-dokument/artikelkatalog/ ovrigt/2016-12-14.pdf [Accessed Apr 2021].

42 Flenady V, Middleton P, Smith GC, et al. Stillbirths: the way forward in high-income countries. Lancet 2011;377:1703-17.

43 Levy M, Kovo M, Barda G, et al. Reduced fetal movements at term, low-risk pregnancies: is it associated with adverse pregnancy outcomes? ten years of experience from a single tertiary center. Arch Gynecol Obstet 2020;301:987-93.

44 Carroll L, Gallagher L, Smith V. Risk factors for reduced fetal movements in pregnancy: a systematic review and meta-analysis. Eur J Obstet Gynecol Reprod Biol 2019;243:72-82.

45 Moore TR, Piacquadio K. A prospective evaluation of fetal movement screening to reduce the incidence of antepartum fetal death. Am J Obstet Gynecol 1989;160:1075-80.

46 Flenady V, Koopmans L, Middleton P, et al. Major risk factors for stillbirth in high-income countries: a systematic review and metaanalysis. Lancet 2011;377:1331-40. 